\title{
Screening of Primer Sets for Amplification Cyclic Lipopeptide Gene of Bacillus Against Banana Fusarium Wilt
}

\author{
Deng Tao ${ }^{1,2}$, Guo Lijia ${ }^{2}$, Yang Laying ${ }^{2}$, Zhou You ${ }^{2}$, Wang Jun ${ }^{2}$, Liu Zhiqiang ${ }^{1}$, Huang Junsheng ${ }^{2} \nabla$ \\ 1 School of Life and Pharmaceutical Sciences, Hainan University, Haikou, 570228, PR. China \\ 2 Key Laboratory of Pests Comprehensive Governance for Tropical Crops, Ministry of Agriculture and Rural Affairs, Environment and Plant Protection \\ Institute, Chinese Academy of Tropical Agricultural Sciences, Haikou, 571101, PR. China \\ $\square$ Corresponding author email: $\underline{\mathrm{h} 888111 @ 126 . \mathrm{com}}$
}

Molecular Microbiology Research, 2021, Vol.11, No.2 doi: $10.5376 / \mathrm{mmr} .2021 .11 .0002$

Received: 16 Nov., 2021

Accepted: 17 Nov., 2021

Published: 28 Nov., 2021

Copyright $\odot 2021$ Deng et al., This article was first published in Molecular Plant Breeding in Chinese, and here was authorized to translate and publish the paper in English under the terms of Creative Commons Attribution License, which permits unrestricted use, distribution, and reproduction in any medium, provided the original work is properly cited.

Preferred citation for this article:

Deng T., Guo L.J., Yang L.Y., Zhou Y., Wang J., Liu Z.Q., and Huang J.S., 2021, Screening of primer sets for amplification cyclic lipopeptide gene of Bacillus against banana fusarium wilt, Molecular Microbiology Research, 11(2): 1-10 (doi: 10.5376/mmr.2021.11.0002)

\begin{abstract}
Cyclic lipopeptides (CLPs) are a class of natural agricultural antibiotics produced by Bacillus, it plays an important role in the biological control using of Bacillus. In this study, 20 strains of Bacillus, including Bacillus amyloliquefaciens, Bacillus subtilis, Bacillus siamese, and Bacillus cereus were determined the antagonistic ability against to pathogenic fungi such as Foc 4. PCR amplification was performed on 20 strains of Bacillus and 7 soil samples, by using the designed 14 pairs of primers for CLPs-related synthetase genes, including Bacillomycin, Fengycins, Iturins, Surfactin etc, screen CLPs primers that can be used for Bacillus and soil monitoring. The results showed that: a total of 16 Bacillus strains have the antagonistic activity against pathogens, and microscopic observation of the crude lipopeptide extract of fermentation broth of these Bacillus strains can destroy the biofilm system and cell wall of Foc4, causing the mycelium and meristems to expand and deform; 12 pairs primers of this study (BamD-F/R, BamA-F/R, FenA-F/R, FenB-F/R, 61FenA-F/R, 61FenB-F/R, ItuA-F/R, ItuB-F/R, ItuC-F/R, ItuD-F/R, SrfAA-F/R, SrfAB-F/R) could effective amplify CLPs gene, and find that all of test Bacillus strains has the ItuC gene, there is a positive relationship between the antagonistic ability of Bacillus and the diversity and richness of CLPs genes, through PCR amplification of total soil DNA, it was found that the designed CLPs primers were feasible to monitor Bacillus in soil environment. It would be used as an important supplement to conventional plate counting and high-throughput sequencing methods, monitor and guide the application of Bacillus control soil-borne diseases of plants to provide theoretical support for further field.
\end{abstract}

Keywords Banana Fusarium Wilt; Antagonistic Bacillus; Cyclic lipopeptide antibiotic gene

As a devastating soil-borne banana disease, Banana Fusarium Wilt is a pathological continuous cropping disease caused by infection of race 1 and race 4 of Fusarium oxysporum f.sp.cubense. At present, the control techniques of banana Fusarium Wilt include breeding for disease resistance, cultivation management, chemical and biological control, etc. Due to the increasingly serious Fusarium Wilt of banana, farmers are forced to blindly use chemical pesticides in the production process, but the control effect of chemical pesticides is not ideal and easy to cause environmental pollution ( $\mathrm{Fu}$ et al., 2016). Biological control technology has the characteristics of being environmentally safe and friendly, resistant to pathogens, improving soil quality and promoting crop growth, and has become an important measure to promote sustainable agricultural development (Chen et al., 2015). The main means of biological control technology is to apply microbial agents with antagonistic ability to pathogenic fungi into the soil of the disease area, including Bacillus spp., Trichoderma spp., Actinomyces spp., etc. (Ma, 2012). Bacillus has become the preferred object of biological control research and commercial production of biopesticides due to its characteristics of forming spores that are easy to be fermented and stored and relatively stable in biological characteristics, as well as its ability to produce antibacterial active substances at all stages of growth (Bais et al., 2004), and has been widely used in production practice.

It is an important way to control soil-borne diseases by controlling the balance of rhizosphere microorganisms with antagonistic Bacillus or its metabolites. The antimicrobial active substances produced by Bacillus metabolism play a key role in biological control, the most representative of which are cyclic lipopeptides (CLPs). The antimicrobial peptides mainly include Bacillomycin, Fengycins, Iturins and Surfactin (Cawoy et al., 2015), 
which have been proved to be safe for human body and have no pollution to the environment (Chen et al., 2008). In addition, studies have shown that CLPs, among the antibacterial substances produced by Bacillus, is the main component that plays an antagonistic role against plant pathogens (Chen et al., 2015), and these substances play an important role in the prevention and control of plant diseases by Bacillus.

Increasing attention is being paid to integrated control techniques for soil-borne diseases such as banana fusarium wilt and overcoming the obstacles of continuous cropping. Therefore, monitoring of beneficial microorganisms and natural products as potent biopesticides in soil is of vital importance. For example, a recent study confirmed the presence of iturin, fengycin, and surfactin-type CLPs in lettuce rhizosphere soils (Chowdhury et al., 2015). However, the monitoring of CLPs, which plays a key role in the prevention and control of soil-borne diseases in soil, has been rarely reported. As beneficial microorganisms must be able to colonize in large numbers in rhizosphere soil, beneficial functional genes such as CLPs also need to be maintained in sufficient numbers in rhizosphere soil to play their roles (Tarkka et al., 2008).

In this study, 14 CLPs synthase genes were amplified by PCR using genomic DNA of Bacillus with broad spectrum resistance as the template to analyze the coverage of these genes in the tested Bacillus, and the feasibility of monitoring CLPs synthase genes in soil was discussed by PCR amplification using genomic DNA of multiple soil sites as the template. Whether it can be used as an important supplement to conventional coating plate counting and high-throughput sequencing methods to lay a foundation for monitoring the content and expression of beneficial microorganisms with this functional gene in soil, and provide theoretical support for comprehensive field prevention and control.

\section{Results and Analysis}

\subsection{Effects of different living bacteria of bacillus on the growth of pathogenic fungi}

According to the method of Wang et al. (2018), the antagonistic activity of 20 strains of Bacillus BQA2 against 7 pathogenic fungi such as Foc4 was determined (Table 1). Among the tested Bacillus, the antagonistic strains of Fusarium oxysporum (Foc4-B2, Fol), Anthracis (Colletotrichum gloeosporioides), Phytophthora litchis (P. litchi, P. nicotianae) and Rhizopteris (P. musarum) showed antagonistic activity to $80 \%$ of the tested pathogens. Except strains BNA, 168, SD20 and GL05, all the other bacillus strains showed certain antagonistic activity against the tested pathogenic fungi, and had good antibacterial broad-spectrum. However, there were significant differences $(P<0.05)$ in the antagonistic activity against different pathogenic fungi, and generally showed good antagonistic activity against Anthrax, followed by Fusarium oxysporum and Phytophthora nicotiana, and most of them were $P$. musarum and $P$. litchi. By comparing the diameters of different bacillus strains against pathogenic fungi, it was found that strain QB33 had the best antagonistic effect against Foc4, BC had the best antagonistic effect against Fol, QB12 had the best antagonistic effect against C.g.Mango, X5 had the best antagonistic effect against C. $g$. Litchi, BQA2 had the best antagonistic effect against C. g. Litchi. C200 had the best antagonistic effect on $P$. nicotianae, CL25 had the best antagonistic effect on P. musarum, and SS1, which had antagonistic effect on other pathogenic fungi, had no antagonistic effect on $P$. litchi. Through this experiment, the antagonistic activity differences of 20 strains of living Bacillus preserved in laboratory against several pathogenic fungi were studied, among which Bacillus subtilis and Bacillus amyloliquefaciens showed better inhibitory effect.

\subsection{Effects of lipopeptide crude extracts from Bacillus fermentation broth on pathogen Foc4}

Among the tested Bacillus, according to the evaluation method of Saravanakumar et al. (2019), the crude extracts of fermentation broth of strains 168, SD20, GL05 and SS1 showed no inhibition against banana fusarium wilt pathogenic fungi, and the inhibition level was evaluated as follows: Strain BC showed a very high inhibitory effect on Foc4 (++++), and strains X5, C200, BQA2, QB12, QB33, QB61, 6051, No.9, CL25, E51 showed a high inhibitory effect on Foc4 (+++). Strains BLG01 and Me showed moderate inhibition to Foc4 (++).

Scanning electron microscopy was used to observe Foc4 treated with control (normal growth) and antagonistic crude lipopeptides of Bacillus. It was found that the crude lipopeptides of Bacillus could destroy the external structure of $F$. oxysporum and inhibit its growth and development. From the control group, the mycelia surface 
was dense, smooth, uniform and full, and the mycelia were complete. The mycelia surface at the edge of the inhibition zone was rough, wrinkled, deformed, and the integrity was destroyed, and the phenomenon of expansion, malformation, and incomplete spore development occurred (Figure 1).

Table 1 Diameter of inhibition zone of different bacillus to pathogenic fungi $(\mathrm{cm})$

\begin{tabular}{|c|c|c|c|c|c|c|c|}
\hline Strains & Foc4-B2 & Fol & C.g.Mango & C. g. Litchi & P. litchi & P. nicotianae & P. musarum \\
\hline BQA2 & $1.74 \pm 0.01 \mathrm{abc}$ & $1.55 \pm 0.10 \mathrm{ab}$ & $1.50 \pm 0.18 \mathrm{a}$ & $1.86 \pm 0.14 \mathrm{ab}$ & $1.27 \pm 0.25 \mathrm{a}$ & $1.53 \pm 0.12 \mathrm{cde}$ & $1.23 \pm 0.12 \mathrm{ab}$ \\
\hline BLG01 & $1.28 \pm 0.03 \mathrm{fg}$ & $1.43 \pm 0.28 \mathrm{bcd}$ & $1.17 \pm 0.15 b c$ & $1.84 \pm 0.16 \mathrm{ab}$ & $1.03 \pm 0.12 \mathrm{abc}$ & $1.7 \pm 0.16 \mathrm{bcd}$ & $0.98 \pm 0.06 \mathrm{~cd}$ \\
\hline C200 & $1.51 \pm 0.01 \mathrm{de}$ & $1.30 \pm 0.05 \mathrm{cde}$ & $1.13 \pm 0.12 b c$ & $1.63 \pm 0.13 \mathrm{c}$ & $0.77 \pm 0.09 \mathrm{bc}$ & $2.57 \pm 0.26 \mathrm{a}$ & $0.93 \pm 0.09 \mathrm{~cd}$ \\
\hline QB12 & $1.88 \pm 0.02 \mathrm{ab}$ & $1.55 \pm 0.05 \mathrm{ab}$ & $1.55 \pm 0.04 \mathrm{a}$ & $1.71 \pm 0.09 \mathrm{bc}$ & $0.80 \pm 0.08 \mathrm{bc}$ & $2.07 \pm 0.21 \mathrm{~b}$ & $1.30 \pm 0.04 \mathrm{ab}$ \\
\hline QB33 & $1.93 \pm 0.08 \mathrm{a}$ & $1.50 \pm 0.05 \mathrm{ab}$ & $1.53 \pm 0.21 \mathrm{a}$ & $1.83 \pm 0.08 \mathrm{ab}$ & $0.73 \pm 0.05 \mathrm{c}$ & $1.70 \pm 0.22 \mathrm{bcd}$ & $1.32 \pm 0.13 \mathrm{a}$ \\
\hline QB61 & $1.28 \pm 0.08 \mathrm{fg}$ & $1.40 \pm 0.05 \mathrm{bcd}$ & $1.33 \pm 0.06 \mathrm{abc}$ & $1.81 \pm 0.09 \mathrm{ab}$ & $0.83 \pm 0.12 b c$ & $1.67 \pm 0.25 \mathrm{bcd}$ & $1.23 \pm 0.09 \mathrm{ab}$ \\
\hline $\mathrm{H} 2$ & $1.70 \pm 0.05 \mathrm{bc}$ & $1.45 \pm 0.05 b c$ & $1.37 \pm 0.12 \mathrm{ab}$ & $1.93 \pm 0.13 \mathrm{a}$ & $1.03 \pm 0.12 \mathrm{abc}$ & $1.83 \pm 0.26 \mathrm{bcd}$ & $1.25 \pm 0.15 \mathrm{ab}$ \\
\hline $\mathrm{X} 5$ & $1.58 \pm 0.43 \mathrm{cde}$ & $1.43 \pm 0.03 \mathrm{bcd}$ & $1.33 \pm 0.08 \mathrm{abc}$ & $1.94 \pm 0.11 \mathrm{a}$ & $1.17 \pm 0.12 \mathrm{ab}$ & $1.77 \pm 0.12 \mathrm{bcd}$ & $1.27 \pm 0.15 \mathrm{ab}$ \\
\hline BNA & $0.00 \mathrm{~h}$ & $0.00 \mathrm{~g}$ & $0.00 \mathrm{~d}$ & $0.00 \mathrm{f}$ & $0.00 \mathrm{~d}$ & $0.00 \mathrm{f}$ & $0.00 \mathrm{e}$ \\
\hline SS1 & $1.16 \pm 0.06 \mathrm{~g}$ & $1.15 \pm 0.10 \mathrm{ef}$ & $1.07 \pm 0.09 \mathrm{c}$ & $1.41 \pm 0.09 \mathrm{e}$ & $0.00 \mathrm{~d}$ & $1.13 \pm 0.21 \mathrm{e}$ & $0.80 \pm 0.16 \mathrm{~d}$ \\
\hline $\mathrm{Me}$ & $1.18 \pm 0.03 \mathrm{~g}$ & $1.30 \pm 0.15 \mathrm{cde}$ & $1.30 \pm 0.21 \mathrm{abc}$ & $1.71 \pm 0.09 \mathrm{bc}$ & $0.87 \pm 0.17 \mathrm{abc}$ & $1.40 \pm 0.16 \mathrm{de}$ & $0.98 \pm 0.08 \mathrm{~cd}$ \\
\hline 168 & $0.00 \mathrm{~h}$ & $0.00 \mathrm{~g}$ & $0.00 \mathrm{~d}$ & $0.00 \mathrm{f}$ & $0.00 \mathrm{~d}$ & $0.00 \mathrm{f}$ & $0.00 \mathrm{e}$ \\
\hline 6051 & $1.30 \pm 0.10 \mathrm{fg}$ & $1.20 \pm 0.05 \mathrm{ef}$ & $1.27 \pm 0.10 \mathrm{abc}$ & $1.47 \pm 0.03 \mathrm{de}$ & $0.95 \pm 0.39 \mathrm{abc}$ & $1.53 \pm 0.12 \mathrm{cde}$ & $1.30 \pm 0.08 \mathrm{ab}$ \\
\hline $\mathrm{BC}$ & $1.55 \pm 0.05 \mathrm{cde}$ & $1.64 \pm 0.01 \mathrm{a}$ & $1.53 \pm 0.23 \mathrm{a}$ & $1.71 \pm 0.09 \mathrm{bc}$ & $1.10 \pm 0.08 \mathrm{abc}$ & $1.33 \pm 0.12 \mathrm{de}$ & $1.20 \pm 0.08 \mathrm{ab}$ \\
\hline TW & $1.55 \pm 0.10 \mathrm{cde}$ & $1.28 \pm 0.03 \mathrm{de}$ & $1.25 \pm 0.08 \mathrm{abc}$ & $1.64 \pm 0.06 \mathrm{c}$ & $0.97 \pm 0.17 \mathrm{abc}$ & $1.40 \pm 0.08 \mathrm{de}$ & $1.28 \pm 0.08 \mathrm{ab}$ \\
\hline NO.9 & $1.63 \pm 0.02 \mathrm{~cd}$ & $1.30 \pm 0.05 \mathrm{cde}$ & $1.37 \pm 0.06 \mathrm{ab}$ & $1.83 \pm 0.13 \mathrm{ab}$ & $1.17 \pm 0.26 \mathrm{ab}$ & $2.00 \pm 0.08 b c$ & $1.08 \pm 0.08 \mathrm{ba}$ \\
\hline CL25 & $1.40 \pm 0.15 \mathrm{ef}$ & $1.18 \pm 0.03 \mathrm{ef}$ & $1.40 \pm 0.18 \mathrm{ab}$ & $1.74 \pm 0.06 \mathrm{bc}$ & $1.07 \pm 0.17 \mathrm{abc}$ & $1.50 \pm 0.08 \mathrm{ecd}$ & $1.33 \pm 0.05 \mathrm{a}$ \\
\hline E51 & $1.43 \pm 0.18 \mathrm{ef}$ & $1.10 \pm 0.08 \mathrm{f}$ & $1.33 \pm 0.10 \mathrm{abc}$ & $1.59 \pm 0.06 \mathrm{~cd}$ & $1.10 \pm 0.08 \mathrm{abc}$ & $2.17 \pm 0.29 \mathrm{ab}$ & $0.88 \pm 0.08 \mathrm{~cd}$ \\
\hline SD20 & $0.00 \mathrm{~h}$ & $0.00 \mathrm{~g}$ & $0.00 \mathrm{~d}$ & $0.00 \mathrm{f}$ & $0.00 \mathrm{~d}$ & $0.00 \mathrm{f}$ & $0.00 \mathrm{e}$ \\
\hline GL05 & $0.00 \mathrm{~h}$ & $0.00 \mathrm{~g}$ & $0.00 \mathrm{~d}$ & $0.00 \mathrm{f}$ & $0.00 \mathrm{~d}$ & $0.00 \mathrm{f}$ & $0.00 \mathrm{e}$ \\
\hline
\end{tabular}

Note: Different lowercase letters in the same column represent significant difference $(p<0.05)$
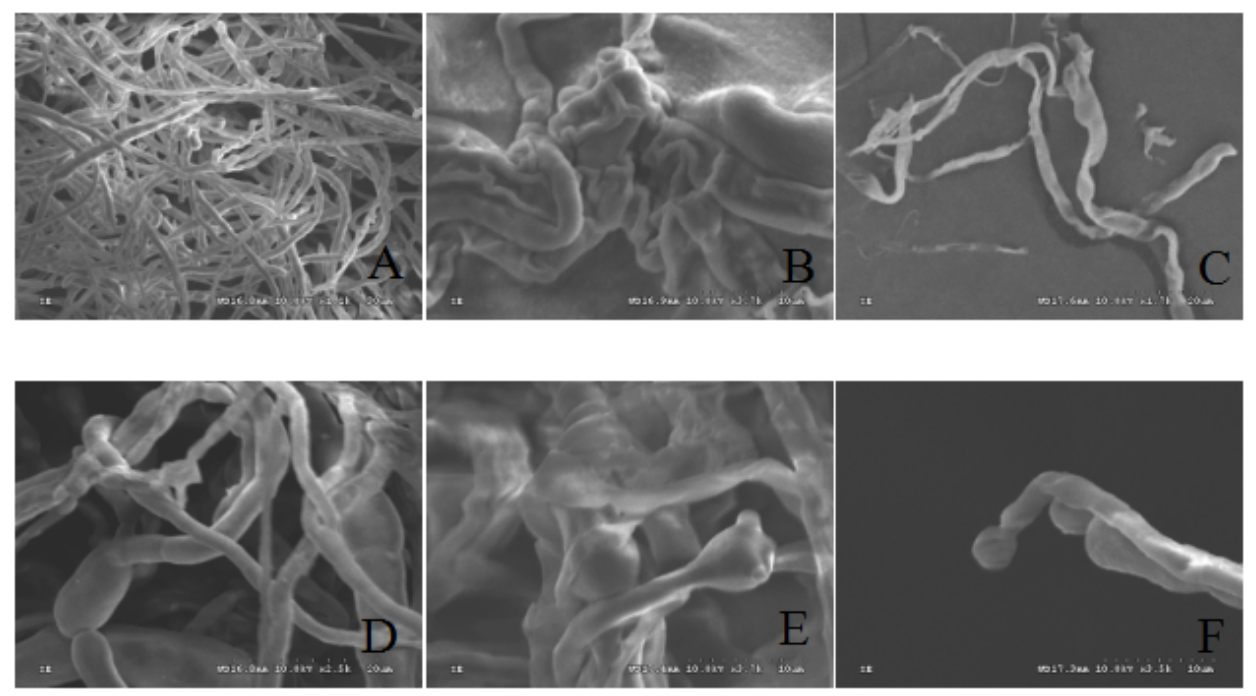

Figure 1 Scanning electron microscopy results of the crude extract of Bacillus fermentation broth against Foc4 Note: A: Control; B,C,D,E,F: Treatment by CLPs

Antagonistic Bacillus can secrete some antibacterial substances acting on the biofilm system, destroy the cell structure of pathogenic fungi, so that pathogenic fungi can not grow and reproduce normally, lose its pathogenicity, so as to reduce the occurrence of diseases. Transmission electron microscopy (TEM) observed that pathogen Foc 4 in the control group was not affected by antagonism of Bacillus, and its cell structure was complete and clear in shape, with complete nucleus, complete organelle types and obvious cell structure boundaries (Figure 2). In the treatment group, the pathogen of banana fusarium wilt was antagonized by crude lipopeptide extracts, and there was no discernible organelle structure. In $\mathrm{C}$, the membrane and cell wall showed a similar phenomenon of "plasma wall separation", and the membrane was obviously incomplete; in D, the membrane disappeared, and the cell wall showed cleavage. 

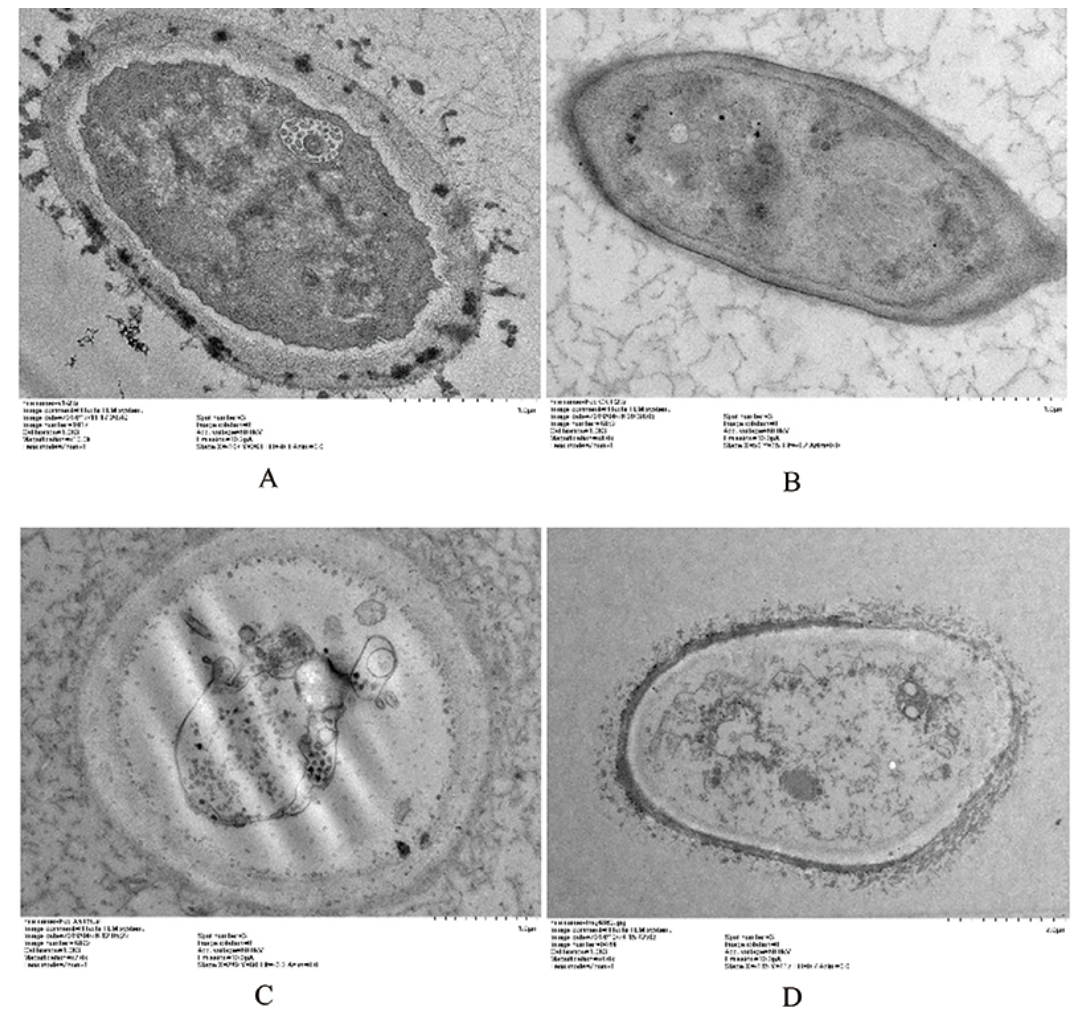

Figure 2 Transmission electron microscope results of the crude extract of Bacillus fermentation broth against Foc4 Note: A,B:Control; C,D: Treatment by CLPs

\subsection{PCR amplification of lipopeptide antibiotic genes of Bacillus}

By optimizing the PCR program (Table 3), the optimal PCR reaction program was obtained as follows: pre-denaturation at $94^{\circ} \mathrm{C}$ for $3 \mathrm{~min}$, denaturation at $95^{\circ} \mathrm{C}$ for $45 \mathrm{~s}$, annealing at $60^{\circ} \mathrm{C}$ (ItuA at $65^{\circ} \mathrm{C}$ ) for $45 \mathrm{~s}$, extension at $72^{\circ} \mathrm{C}$ for $1 \mathrm{~min}, 30$ cycles, and extension at $72^{\circ} \mathrm{C}$ for $5 \mathrm{~min}$. Using this program to amplify CLPs related synthesis gene sequences. It was found that 12 pairs of designed primers could effectively amplified the CLPs gene of Bacillus spp. (BamD-F/R, BamA-F/R, FenA-F/R, FenB-F/R, 61FenA-F/R, 61FenB-F/R, ItuA-F/R, ItuB-F/R, ItuC-F/R, ItuD-F/R, SrfAA-F/R, SrfAB-F/R), the antagonistic Bacillus could amplify ItuC gene of the 20 strains of Bacillus, $80 \%$ could be amplified to BamD, $90 \%$ to BamA, $80 \%$ to FenA, $90 \%$ to FenB, $25 \%$ to $61 \mathrm{FenA}, 45 \%$ to $61 \mathrm{FenB}$ and $45 \%$ to ItuA. $95 \%$ of ItuB, $100 \%$ of ItuC, $65 \%$ of ItuD, $65 \%$ of SrfAA and $85 \%$ of $\mathrm{SrfAB}$ could be amplified. $\mathrm{MycF}$ and MycA could not be amplified to the target band, among which ItuC had the highest coverage. BamD, BamA, FenB and ItuA had the highest specificity (Figure 3).

\subsection{Gene amplification of lipopeptide antibiotics in Bacillus soil}

Tiangen Soil DNA Extraction Kit extracted soil DNA for CLPs gene PCR amplification (Figure 3; Figure 4), it was found that lipopeptide antibiotic genes could be amplified to a certain extent in all soil samples. In the tested soil samples, the amplification efficiency and specificity of Hainan red loam were the best, which was related to the application of microbial fertilizer rich in antagonistic bacillus. The primers BamA, FenB, ItuC and SrfAA of Hainan soil samples with the best specificity were selected to send the amplified products for sequencing. The amplified products had high homology with the genes obtained in NCBI. The results of $704 \mathrm{bp}$ PCR showed that the bamA-F/R primer had $99 \%$ homology with the gene involved in Bacillomycin biosynthesis. Fenb-F/R primers were $99 \%$ homologous to a region of 715 bp PCR products and Fengycin biosynthetic operon. Analysis of the 640 bp PCR product with itUC-F/R primer showed that the primer was $99 \%$ homologous to a region of the operon biosynthesized by Iturin. The 816 bp PCR product was analyzed using srfaa-F/R primers and showed $98 \%$ homology to a region of SrfAA associated with Surfactin biosynthesis. Bacillomycin, Fengycin, Iturin and Surfactin antibiotic genes were found in soil of many places in China. Through this experiment, the possibility of lipopeptide antibiotic gene amplification in soil can be determined. 


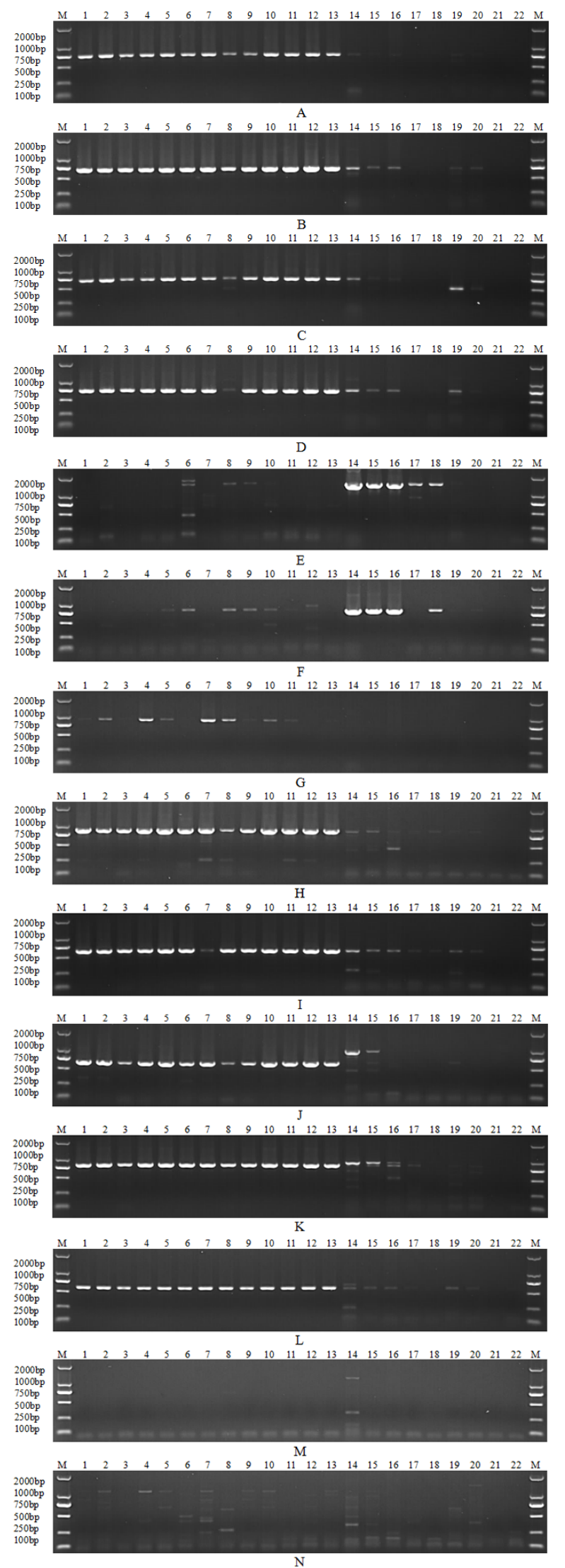

Figure 3 PCR products of CLPs genes of 20 strains of Bacillus

Note: M: DL2000 DNA Marker; 1 20: BQA2, BLG01, C200, QB12, QB33, H2, Me, BC, TW E51, NO.9, CL25, X5, QB61, 6051, 168, BNA, SS1, SD20, GL05 genomic DNA; 21,22: Negative control (ddH $\left.\mathrm{d}_{2} \mathrm{O}\right)$;A N Primer of CLPs:BamD, BamA, FenA, FenB, 61-FenA, 61-FenB, ItuA, ItuB, ItuC, ItuD, SrfAA, SrfAB, MycF, MycA 

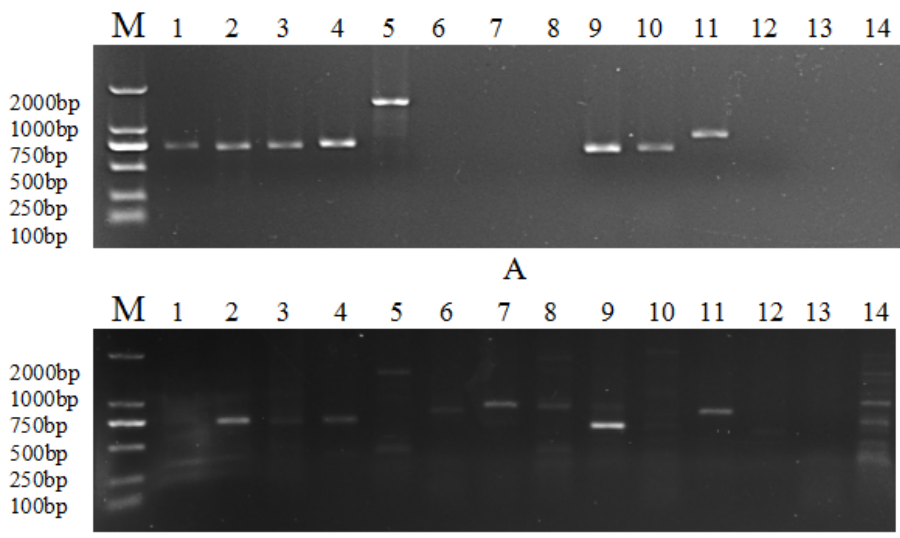

B
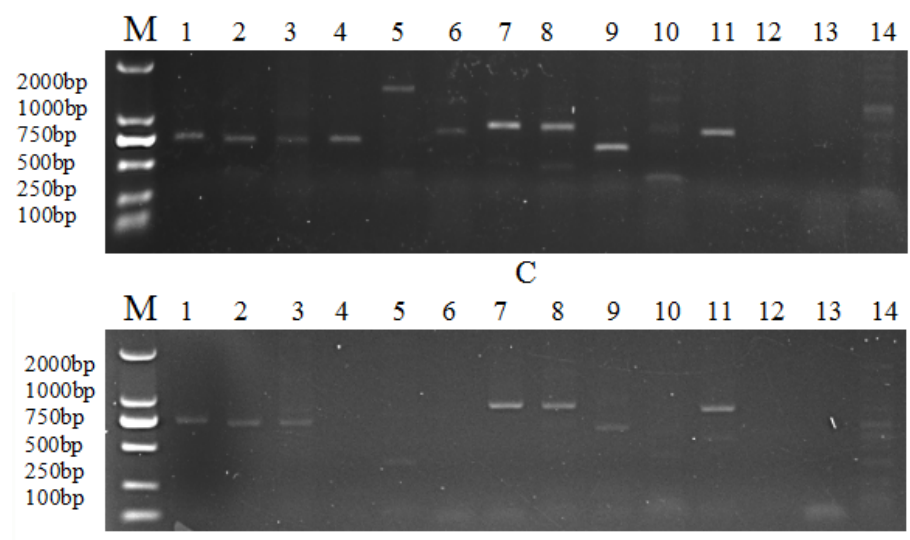

D

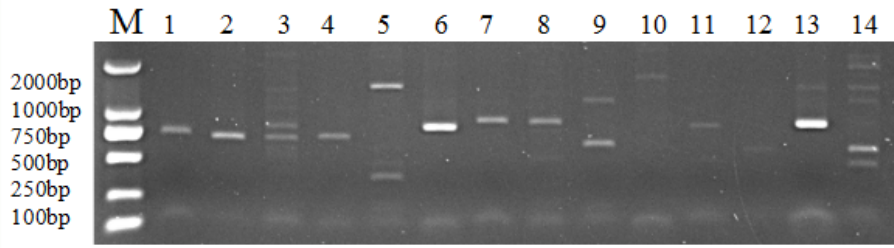

E
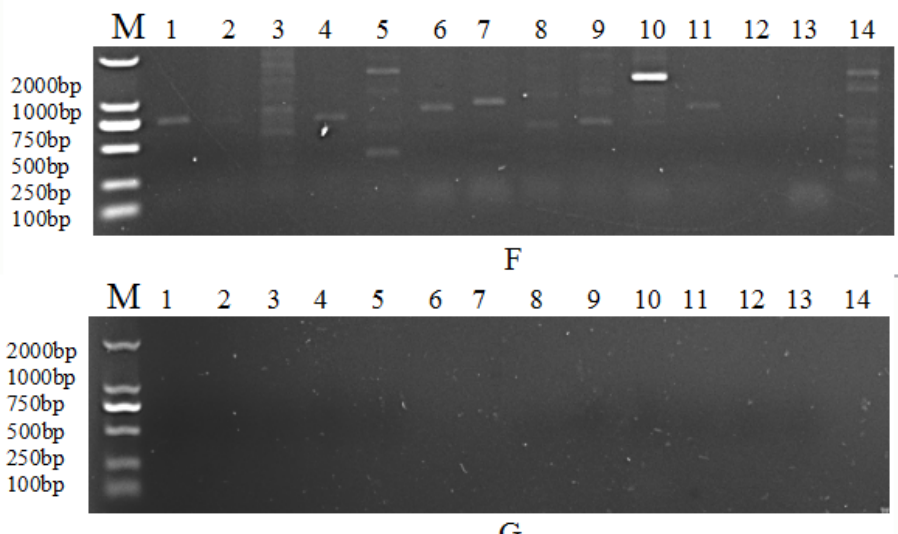

G

Figure 4 PCR products of lipopeptide antibiotic genes in multiple soils

Note: M: DL2000 DNA Marker; 1 14 Primer of CLPs: BamD, BamA, FenA, FenB, 61-FenA, 61-FenB, ItuA, ItuB, ItuC, ItuD, SrfAA, SrfAB, MycF, MycA; A G: Red soil samples from Hainan, red soil from Jiangxi, red soil from Zhejiang, sandy soil from Hebei, desert soil from Gansu, gray soil from Xinjiang and $\mathrm{ddH}_{2} \mathrm{O}$

\section{Discussion}

Bacteriostasis proteins, bacteriostasis polypeptides and bacteriostasis lipopeptides are the main bacteriostasis active substances secreted by Bacillus (Yang et al., 2015), among which lipopeptide antibiotics represented by Iturins and Fengycins are the important active substances against fungi (Falardeau et al., 2013). These lipopeptide 
antibiotics can destroy the cell membrane by interacting with the membrane, leading to leakage of cytoplasm.It can also inhibit the synthesis of glucan, peptidoglycan and chitin, which are important components of cell wall, leading to the obstruction of cell wall formation of pathogenic fungi, cytoplasm leakage and protoplast exposure. This results in the cleavage of pathogenic fungi (such as hyphae, conidia or zoospores) at different life stages (Saravanakumar et al., 2019).

The results of scanning electron microscopy and transmission electron microscopy showed that the antagonistic lipopeptide crude extracts of fermentation broth could cause the mycelia of pathogenic fungi to appear rough surface, shrinkage, malformation, integrity destruction, expansion of meristem nodes, malformation and incomplete spore development. The pathogenic fungi treated with crude extracts showed similar phenomena of "plasmal-wall separation", unclear organelle structure boundary, cell membrane destruction, cell wall lysis and so on. This phenomenon is consistent with the results of Arrebola et al. (2010), indicating that antagonistic bacillus can secrete lipopeptide antibiotics (CLPs) to show the ability to inhibit a variety of pathogenic fungi including banana fusarium wilt. PCR detection of CLPs gene of the tested Bacillus showed that the 14 pairs of primers designed had a significant amplification efficiency on the 20 tested bacillus strains. Among them, the species and abundance of lipopeptide antibiotic genes of bacillus with high bacteriostatic ability in the in vivo confrontation test were also relatively high. And crude extracts from fermented liquid of Foc4 Bacillus with high inhibition can amplify a certain number of CLPs synthetic gene segments, and can swell to CLPs gene types and abundance, the higher its inhibition also stronger, it shows high pathogenic fungus inhibition and fat gene diversity and richness of peptide antibiotics has positive contact. The results of this study are consistent with those of Cao (2016). The diversity and abundance of lipopeptide antibiotic genes can also be used as a condition for screening biocontrol bacillus strains and predicting their antagonistic potential.

Some studies have found that factors such as temperature, ultraviolet light, acid base and protease have varying degrees of influence on CLPs (Lian et al., 2011), which makes it difficult to obtain CLPs information directly from the complex soil environment. Interestingly, Surfactin had poor inhibitory activity against fungi directly, but synergistically acted with Iturin to induce systemic resistance in plants and exhibited strong inhibitory activity against F. oxysporum, as well as lethal action against root-knot nematodes (Meena et al., 2016). Moreover, it is conducive to the colonization of rhizosphere soil and roots of bacteria, which is also the key and prerequisite for the sustained effect of antagonistic bacillus and the successful control of plant pathogenic fungi (Kavitha et al., 2005). Therefore, it is necessary to monitor multiple CLPs synthesis genes. In this study, primers of CLPs related synthetic genes were used for PCR amplification of soil total DNA to directly obtain the information of CLPs related synthetic genes in soil, which is an important antibacterial active substance. The results of genomic DNA amplification in soil samples showed that CLPs synthetic gene was feasible in soil detection, which provided a reference for quantitative or semi-quantitative monitoring of this beneficial functional gene in soil in the future.

\section{Materials and Methods}

\subsection{Tested strains}

The tested strains included Fusarium oxysporum f.sp. cubense Race 4, Foc4, (B2 strain), Fusarium oxysporum f.sp. lycopersici (Fol), Colletotrichum gloeosporioides Pen (C.g. Mango), Colletotrichum gloeosporioides Penz (C. g. Litchi), Peronophthora litchi (P. litchi), Phytophthora nicotianae (P. nicotianae), and Phyllosticta musarum (P. musarum) (Table 2). They were isolated or preserved by our laboratory (Laboratory of Microbial Resources Research and Utilization, Institute of Environment and Plant Protection, Chinese Academy of Tropical Agricultural Sciences).

\subsection{Media, reagents and instruments}

LB medium, PDA medium, laboratory fermentation medium (AYTK medium): sucrose $20 \mathrm{~g}$, soybean meal $10 \mathrm{~g}$, yeast powder $1 \mathrm{~g}$, distilled water $1 \mathrm{~L}$, natural $\mathrm{pH}$.

Sangon ${ }^{\circledR E z u p ~ C o l u m n ~ B a c t e r i a l ~ D N A ~ P u r i f i c a t i o n ~ K i t, ~ T i a n g e n ~}{ }^{\circledR S o i l ~ G e n o m i c ~ D N A ~ E x t r a c t i o n ~ K i t, ~ T i a n g e n ~}$ ${ }^{R} 2 \times$ Taq PCR Mix, other reagents purchased from Chinese medicine. Bio-Rad T100 PCR instrument, Hitachi 
${ }^{\mathrm{TM}} 4000$ Plus desktop scanning electron microscope, HT-7700 transmission electron microscope, VILBER Fusion FX7 Spectra multifunctional imaging system.

Table 2 Antagonistic Bacillus in this study

\begin{tabular}{lll}
\hline Strains & Source or reference & Classification \\
\hline BQA2 & Wild Forest Soil in Bawangling, Hainan & B. amyloliquefaciens \\
BLG01 & Rhizosphere soil of bananas in Wenchang, Hainan & B. amyloliquefaciens \\
C200 & Mangrove soil in Wenchang, Hainan & B. amyloliquefaciens \\
QB12 & Sandy soil in Dongfang Banqiao Town, Hainan & B. amyloliquefaciens \\
QB33 & & B. amyloliquefaciens \\
QB61 & Mangrove soil in Wenchang, Hainan & B. subtilin \\
H2 & Banana Root System, Hainan & B. amyloliquefaciens \\
X5 & Mouse feces & B. amyloliquefaciens \\
SS1 & Rhizosphere soil of banana in Danzhou, Hainan & B. subtilin \\
BNA & Banana field soil in Honghe, Yunnan & B. subtilin \\
Me & Fujian Academy of Agricultural Sciences & B. amyloliquefaciens \\
168 & & B. subtilin \\
6051 & Microbial agent of BaoCui & B. subtilin \\
BC & Microbial agent from TaiWan & B. siamensis \\
TW & Rhizosphere soil of banana in Hai'an, Guangdong & B. amyloliquefaciens \\
NO.9 & Banana root system in Zhanjiang, Guangdong & B. amyloliquefaciens \\
CL25 & Soil of Banana Garden in Dongfang, Hainan & B. amyloliquefaciens \\
E51 & Molasses & B. cereus \\
SD20 & Soil of Banana Garden in Guilin, Guangxi & B. cereus \\
GL05 & &
\end{tabular}

\subsection{Determination of antagonistic activity of Bacillus}

According to the antagonistic activity detection method proposed by Wang et al. (2018), the antagonistic activity of active Bacillus was measured. For each pathogen fungus, pathogen fungi were obtained by shaking flask or plate culture of PDA liquid, and spore suspension was prepared. Using inverted plate method, spore suspension was added into the PDA medium which was about to solidify and shaken evenly. The final concentration was about $10^{6} \mathrm{cfu} / \mathrm{mL}$, and then the spores were inoculated with $0.5 \mathrm{~cm}$ Bacillus cake, and cultured at $28^{\circ} \mathrm{C}$ for $3 \sim 4 \mathrm{~d}$. The diameter of antagonist circle was observed and recorded.

Referring to the method of Yang et al. (2015), crude lipopeptide substances were extracted from Bacillus fermentation broth, and the antagonistic activity of Foc4 was measured. $150 \mu \mathrm{L}$ crude extract of Bacillus fermentation broth with bactericidal filter membrane was added into $0.5 \mathrm{~cm}$ hole, and cultured at $28^{\circ} \mathrm{C}$ for $4 \sim 7 \mathrm{~d}$ to observe the size of antagonistic circle. Referring to the evaluation method of Saravanakumar et al. (2019), the inhibition level evaluation was as follows: the antagonistic zone less than $1 \mathrm{~mm}$ was no inhibition; When the antagonistic zone was less than $2 \mathrm{~mm}$, the inhibition was low (+). The antagonistic zone between 2 and $3 \mathrm{~mm}$ was moderate $(++)$. The antagonistic zone between $3 \mathrm{~mm}$ and $4 \mathrm{~mm}$ showed high inhibition $(+++)$. The inhibition of the antagonistic bands larger than $4 \mathrm{~mm}$ was very high $(++++)$. Mycelia on the medium with edge of antagonistic zone of strain X5 were selected for preparation (Chen, 2018), and observed by SCANNING electron microscopy and transmission electron microscopy to analyze its antagonistic mechanism.

\subsection{Gene amplification of bacillus lipopeptide antibiotics}

Gene sequences of lipopeptide antibiotics such as Bacilin were downloaded from GenBank and compared with the whole genome of tested Bacillus. Primers were designed using Primer Premier 5.0 for high-homology segments selected (Table 3). Bacterial DNA extraction kit was used to extract bacillus genomic DNA, and 14 CLPs related synthetic genes were detected by PCR. The reaction system was $20 \mu \mathrm{L}$ : Mix $10 \mu \mathrm{L}$, upstream and downstream primers $(10 \mu \mathrm{mol} / \mathrm{L}) 0.5 \mu \mathrm{L}$ each, DNA template $1 \mu \mathrm{L}$, and $\mathrm{ddH}_{2} \mathrm{O}$ supplement to $20 \mu \mathrm{L}$. The PCR reaction sequence was as follows: pre-denaturation at $94^{\circ} \mathrm{C}$ for $3 \mathrm{~min}$, denaturation at $95^{\circ} \mathrm{C}$ for $45 \mathrm{~s}$, annealing at 
$50^{\circ} \mathrm{C} \sim 65^{\circ} \mathrm{C}$ for $45 \mathrm{~s}$, extension at $72^{\circ} \mathrm{C}$ for $1 \mathrm{~min}, 30$ cycles, and extension at $72^{\circ} \mathrm{C}$ for $5 \mathrm{~min}$. After PCR, PCR products were detected by $1.5 \%$ agarose gel electrophoresis.

Table 3 Primer information of lipopeptide antibiotics from Bacillus

\begin{tabular}{|c|c|c|c|c|c|}
\hline Antibiotic & Primer name & Refseq & Position & Product size $(\mathrm{bp})$ & Sequence $\left(5^{\prime}-3^{\prime}\right)$ \\
\hline \multirow[t]{4}{*}{ Bacillomycin } & BamD-F & AY137375 & $1227-1247$ & 729 & TTCAGGATGCCGTTACACTTG \\
\hline & BamD-R & & 1934-1955 & & GCGTCGTCATATTGGAATAAG \\
\hline & BamA-F & & $13269-13289$ & 704 & ATCAAGAGCCAGGAAGCGTAT \\
\hline & BamA-R & & $13950-13972$ & & GCCGATAGGATGTGTAAGTAGTC \\
\hline \multirow[t]{4}{*}{ Fengycin } & FenA-F & BGC000109 & 29109-29129 & 697 & GTCTTGTAACGGCACCTGAAC \\
\hline & FenA-R & 5 & $29782-29803$ & & TGTATTAGATAGCGGAGGAACC \\
\hline & FenB-F & & $32280-32299$ & 715 & GCTCCATTCACGCTCCTCTT \\
\hline & FenB-R & & 32973-32994 & & CCGCATCTCTTCCAATCTTCTG \\
\hline \multirow[t]{4}{*}{ QB61-fengycin } & 61-FenA-F & QB61_0195 & $801-822$ & 1424 & GCAGCAATATAACCGCACAGA \\
\hline & 61-FenA-R & 6 & $2224-2245$ & & CAGCATTCATCAGAGCAGGAG \\
\hline & 61-FenD-F & & $1354-1375$ & 809 & GAGCAACAGGTTATCCAATCGT \\
\hline & 61-FenD-R & & $2162-2181$ & & GCATCGTCAGCAGTCATCAC \\
\hline \multirow[t]{8}{*}{ Iturin } & ItuA-F & KY111358 & $1641-1660$ & 885 & TGCCAGACAGTATGAGGCAG \\
\hline & ItuA-R & & $2506-2525$ & & CATGCCGTATCCACTGTGAC \\
\hline & ItuB-F & AB050629 & $81-100$ & 874 & TAAAGCAGCGGATAAAGCGT \\
\hline & ItuB-R & & $935-954$ & & AATGGCGACTAACGTATCGG \\
\hline & ItuC-F & & $5810-5829$ & 640 & CCGTAATCAACCGTCTCGTT \\
\hline & ItuC-R & & $6430-6449$ & & GGGTGAGCTGCAAACTTCTC \\
\hline & ItuD-F & & $112-131$ & 647 & GATCGGATCTCCTTGGATGT \\
\hline & ItuD-R & & $739-758$ & & ATCGTCATGTGCTGCTTGAG \\
\hline \multirow[t]{4}{*}{ Surfactin } & SrfAA-F & AJ575642 & $13327-13346$ & 816 & GGTTCAGCGGATTCAGCATT \\
\hline & SrfAA-R & & $14122-14142$ & & GGACGGTTGTAGTAGCCTTCT \\
\hline & SrfAB-F & & $19750-19773$ & 586 & CTGGAGCAATCATCATATCGTCAT \\
\hline & SrfAB-R & & 20313-20335 & & ATAGAGCGGCACATAATCATAGC \\
\hline \multirow[t]{4}{*}{ Mycosubtilin } & MycF- R & AF184956 & 2961-2982 & 843 & TCGTCAGGTTGGAATAGGTCTT \\
\hline & MycF- F & & $2140-2163$ & & CGGTTAGTGTTATCGCTTATCAAG \\
\hline & MycA-F & & $12850-12868$ & 1036 & AGCGGTCGTCGGATGTATG \\
\hline & MycA-R & & $13867-13885$ & & AGCAGCGGTCAATCGTTCT \\
\hline
\end{tabular}

\subsection{Gene amplification of lipopeptide antibiotics in soil}

Total DNA of soil samples was extracted by Tiangen Soil DNA Extraction Kit, and PCR amplification was performed with the designed specific CLPs primers. The reaction system was $20 \mu \mathrm{L}$ : Mix $10 \mu \mathrm{L}$, upstream and downstream primers $(10 \mu \mathrm{mol} / \mathrm{L}) 0.5 \mu \mathrm{L}$ each, DNA template $1 \mu \mathrm{L}$, and $\mathrm{ddH}_{2} \mathrm{O}$ supplement to $20 \mu \mathrm{L}$. The PCR reaction sequence was as follows: pre-denaturation at $94^{\circ} \mathrm{C}$ for $3 \mathrm{~min}$, denaturation at $95^{\circ} \mathrm{C}$ for $45 \mathrm{~s}$, annealing at $50^{\circ} \mathrm{C} \sim 65^{\circ} \mathrm{C}$ for $45 \mathrm{~s}$, extension at $72^{\circ} \mathrm{C}$ for $1 \mathrm{~min}, 30 \mathrm{cycles}$, and extension at $72^{\circ} \mathrm{C}$ for $5 \mathrm{~min}$. After PCR, PCR products were detected by $1.5 \%$ agarose gel electrophoresis.

\subsection{Data analysis}

The experimental data were expressed as mean \pm standard deviation $(\mathrm{X} \pm \mathrm{SD})$. SAS9.2 software was used for statistical analysis of the experimental data. One-way analysis of variance was performed for the data, and the difference significance level was $p<0.05$.

\section{Authors' contributions}

DT is the experimental designer and executor of this study. ZZ, YLY and WJ assisted in data analysis and writing the first draft of the paper; GLJ and LZQ participated in experimental design and analysis of experimental results; HJS is the architect and principal of the project, directing experimental design, data analysis, paper writing and revision. All authors read and approved the final manuscript. 


\section{Acknowledgments}

This research was supported by the Special Funds of the National Key Research and Development (2017YFD020060206; 2017YFD0202100), Hainan Natural Science Fund for Innovation Research Team (2017YFD020060206), and High-level Talents Project of Hainan Natural Science Foundation (2019RC283).

\section{Reference}

Arrebola E., Jacobs R., and Korsten L., 2010, Iturin A is the principal inhibitor in the biocontrol activity of Bacillus amyloliquefaciens PPCB004 against postharvest fungal pathogens, J. Appl. Microbiol., 108(2): 386-395 https://doi.org/10.1111/j.1365-2672.2009.04438.x

Bais H.P., Fall R., and Vivanco J.M., 2004, Biocontrol of Bacillus subtilis against infection of Arabidopsis roots by Pseudomonas syringae is facilitated by biofilm formation and surfactin production, Plant Physiol., 134(1): 307-319 https://doi.org/10.1104/pp.103.028712

Cao Z.C., 2016, Construction the multiple screening system of an antagonistic bacillus sp. against banana Fusarium wilt and research on its control effect, Thesis for M.S., Hainan University, Supervisor: Huang J.S., pp.77.

Cawoy H., Debois D., Franzil L., De P.E., Thonart P., and Ongena M., 2015, Lipopeptides as main ingredients for inhibition of fungal phytopathogens by Bacillus subtilis/amyloliquefaciens, Microb. Biotechnol., 8(2): 281-295.

Chen F., Zheng Y., Luo J.M., Han D., and Wang M., 2015, Production and Identification of Antifungal Compounds Produced by Bacillus subtilis B579, In: Zhang T.C., and Nakajima M. (eds), Advances in Applied Biotechnology, Springer, Berlin, Heidelberg, pp.563-570. https://doi.org/10.1111/1751-7915.12238

Chen H., Yuan C., Cai K., Zheng Z.M., and Yu Z.L., 2008, Purification and identification of iturin a from Bacillus subtilis JA by electrospray ionization mass spectrometry, Acta Microbiologica Sinica, 48(1): 116-120

Chen Z.J., 2018, Construction of soil functional microbial community based on disease prevention and growth promotion and optimization of culture conditions, Thesis for M.S., Hainan University, Supervisor: Qi C.L., pp.25

Chowdhury S.P., Uhl J., Grosch R., Alquéres S., Pittroff S., Dietel K., Schmitt K.P., Borriss R., and Hartmann A., 2015, Cyclic lipopeptides of Bacillus amyloliquefaciens subsp. plantarum colonizing the lettuce rhizosphere enhance plant defense responses toward the bottom rot pathogen Rhizoctonia solani, Mol. Plant-Microbe Interact., 28(9): 984-995. https://doi.org/10.1094/MPMI-03-15-0066-R

Falardeau J., Wise C., Novitsky L., and Avis T.J., 2013, Ecological and mechanistic insights into the direct and indirect antimicrobial properties of Bacillus subtilis lipopeptides on plant pathogens, J. Chem. Ecol., 39(7): 869-878 https://doi.org/10.1007/s10886-013-0319-7

Fu L., Ruan Y.Z., Tao C.Y., Li R., and Shen Q.R., 2016, Continous application of bioorganic fertilizer induced resilient culturable bacteria community associated with Banana Fusarium wilt suppression, Sci. Rep., 6(1): 2044-2049 https://doi.org/10.1038/srep27731

Kavitha S., Senthilkumar S., Gnanamanickam S., Inayathullah M., and Jayakumar R., 2005, Isolation and partial characterization of antifungal protein from Bacillus polymyxa strain VLB16, Process Biochem., 40(10): 3236-3243 https://doi.org/10.1016/j.procbio.2005.03.060

Lian L.L., Xie L.Y., Chen J.M., Zheng L.P., and Lin Q.Y., 2011, Colonization of biocontrol strain EN5 and its effects on rhizosphere soil microbial communities, Zhiwu Baohu (Plant Protection), 37(2): 31-35

Ma Y.H., 2012, Study on mechanism of bioeontrol of cucumlaer fusarium wilt with complex microorganism, Thesis for M.S., Hebei Normal University, Supervisor: Zhang L.P., and Zhao B.H., pp.6

Meena K.S., Ramyabharathi S.A., Raguchander T., and Jonathan E.I., 2016, Interaction of meloidogyne incognita and fusarium oxysporum in carnation and physiological changes induced in plants due to the interaction, SAARC J. Agri., 14(1): 59-69 https://doi.org/10.3329/sja.v14i1.29576

Saravanakumar D., Thomas A., and Banwarie N., 2019, Antagonistic potential of lipopeptide producing Bacillus amyloliquefaciens against major vegetable pathogens, Eur. J. Plant Pathol., 154 (2): 319-335 https://doi.org/10.1007/s10658-018-01658-y

Tarkka M., Schrey S., and Hampp R., 2008, Plant associated soil micro-organisms, In: Nautiyal C.S., and Dion P. (eds.), Molecular Mechanisms of Plant and Microbe Coexistence, Springer, Berlin, Heidelberg, pp.5-8 https://doi.org/10.1007/978-3-540-75575-3 1

Wang J., Huang J.S., Liang C.C., Zhou Y., Liu L., Yang L.Y., and Guo L.J., 2018, A method for determining the antagonistic activity of biocontrol bacterial metabolites under non-sterile conditions, Chinese Patent, CN107937479A

Yang R.X., Ji J.H., Wang Z.H., Liu P., Xue D., and Wang Z.Y., 2015, Isolaition, indentification and inhibitory activity of lipopeptides of endophytic bacteria from the root of Paeonia suffruticosa, Weishengwuxue Tongbao (Microbiology), 42(6): 1081-1088 